\title{
Enantioselective Copper-Catalyzed Reductive Coupling of Alkenylazaarenes with Ketones
}

\author{
Aakarsh Saxena, Bonnie Choi, and Hon Wai Lam* \\ EaStCHEM, School of Chemistry, University of Edinburgh, The King's Buildings, West Mains Road, Edinburgh, EH9 3JJ, \\ United Kingdom
}

Supporting Information Placeholder

\begin{abstract}
Catalytic enantioselective methods for the preparation of chiral azaarene-containing compounds are of high value. By combining the utility of copper hydride catalysis with the ability of $\mathrm{C}=\mathrm{N}$-containing azaarenes to activate adjacent alkenes toward nucleophilic additions, the enantioselective reductive coupling of alkenylazaarenes with ketones has been developed. The process is tolerant of a wide variety of azaarenes and ketones, and provides aromatic heterocycles bearing tertiary-alcohol-containing sidechains with high levels of diastereo- and enantioselection.
\end{abstract}

The development of new catalytic reactions for the functionalization of aromatic heterocycles and their derivatives continues to be a valuable endeavor due to the importance of these structures in natural products, pharmaceuticals, agrochemicals, and other molecules of interest. In this regard, recent efforts from our laboratory have targeted the development of processes that exploit the ability of a suitably positioned $\mathrm{C}=\mathrm{N}$ moiety within azaarenes to activate adjacent alkenes toward catalytic enantioselective nucleophilic additions. ${ }^{1,2,3}$ The first of these reports described copper-catalyzed reductions ${ }^{4}$ of $\beta, \beta$ disubstituted 2-alkenylazaarenes, which result in alkylazaarenes with a new stereogenic center at the $\beta$-carbon (representative example in Figure 1A). ${ }^{1}$ Since these reactions likely proceed via the intermediacy of organocopper species that undergo protonation with $t$ - $\mathrm{BuOH}$, we questioned whether these intermediates could be trapped in situ with an alternative electrophile such as a ketone (Figure 1B). Such a reductive coupling process would be synthetically more valuable, delivering more complex tertiary-alcohol-containing products with stereochemistry at both $\alpha$ - and $\beta$-carbons.

Although the proposed process is related to coppercatalyzed reductive aldol reactions described previously, $5,6,7,8,9$ to our knowledge there are no reports of alkenylazaarenes being employed as substrates in these reactions. To date, the only report of catalytic reductive coupling reactions of alkenylazaarenes is that from the Krische group, who described racemic rhodium-catalyzed hydrogenative coupling of vinylazines with $N$-sulfonylaldimines (Figure 1C). ${ }^{10}$ The realization of enantioselective variants of this and related processes would therefore be of obvious value. Herein, we report highly enantioselective copper-catalyzed reductive coupling reactions of alkenylazaarenes with ketones.

This study began with examination of the enantioselective reductive coupling of 2-vinylquinoline (1a) with acetophenone (1.1 equiv) using $\mathrm{PhSiH}_{3}$ (1.2 equiv) as the hydride source, 5 mol $\% \mathrm{Cu}(\mathrm{OAc})_{2} \cdot \mathrm{H}_{2} \mathrm{O}$, and $5 \mathrm{~mol} \%$ of various chiral bisphosphines in toluene (Table 1$).{ }^{4}$ Pleasingly, proof of concept was quickly established, and all ligands evaluated led to

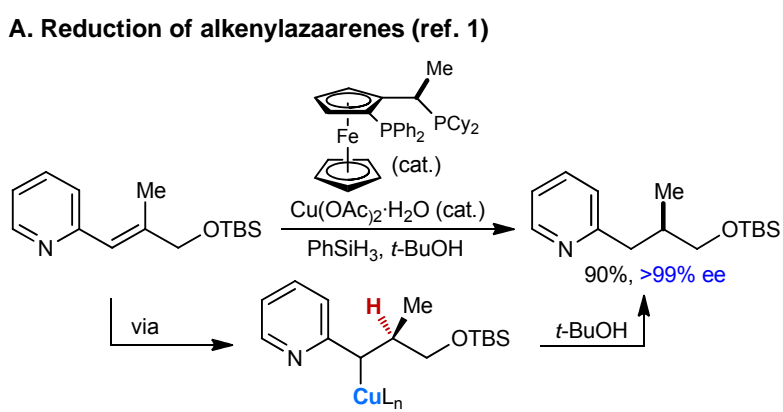

B. Reductive coupling of alkenylazaarenes with ketones (this work)

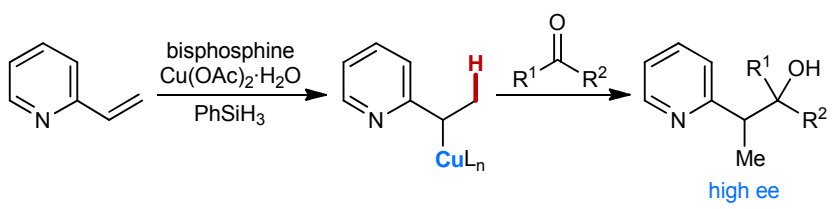

C. Existing reductive coupling of vinylazines (ref. 10)

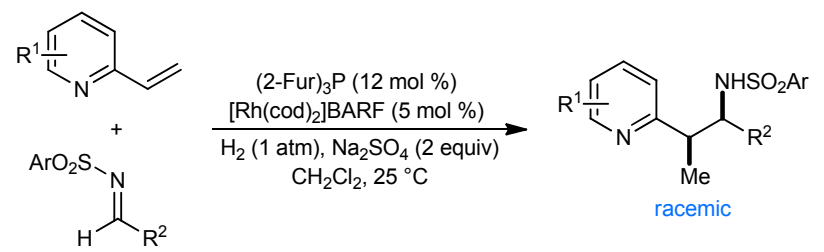

Figure 1. Catalytic transformations of alkenylazaarenes

complete consumption of 1a to provide the coupling product 2a as a mixture of diastereomers, along with traces of the simple reduction product 3. ${ }^{11}$ Enantioselectivities were modest using ligands L1-L3 (entries 1-3), but high using $(R, R)$ Quinox-P* (L4) (entry 4), the Josiphos ligand L5 (entry 5), and the Taniaphos ligand L6 (entry 6). However, no diastereoselectivity was observed in most cases, with the notable exception being the reaction using $\mathbf{L 6}$ which provided 2a in 5:1 dr and $93 \%$ ee for the major isomer (entry 6). Accordingly, L6 was selected for further experimentation.

Chart 1 presents results of reductive coupling of various vinylazaarenes $\mathbf{1 a}-\mathbf{1 h}^{12}$ with a range of ketones. Gratifyingly, the scope of the process is broad, and the enantioselectivities of the products were uniformly high $\left(89->99 \%\right.$ ee). ${ }^{11} \mathrm{Al}-$ though $\mathbf{L 6}$ provided the best results for products $\mathbf{2 a - 2 i}$, this ligand resulted in a low yield in the attempted synthesis of $\mathbf{2} \mathbf{j}$, and poor diastereo- and enantioselectivities in the attempted syntheses of $\mathbf{2 k}$ and $\mathbf{2 l}$. In these cases, $(R, R)$-Quinox-P* (L4) was superior for $\mathbf{2} \mathbf{j}$ and $\mathbf{2 k}$, and the Josiphos ligand $\mathbf{L 5}$ was optimal for $\mathbf{2 l}$. In addition to 1a, effective substrates include 
Table 1. Evaluation of Chiral Bisphosphines ${ }^{a}$
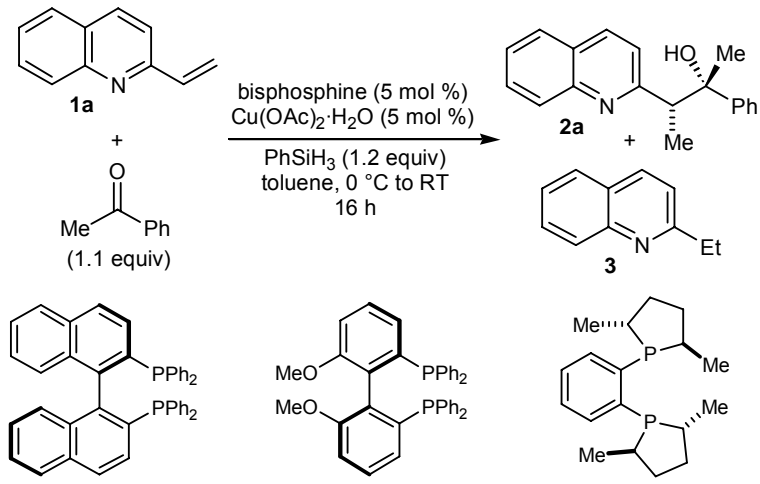

(R-BINAP (L1)

(R)-MeO-BIPHEP (L2)

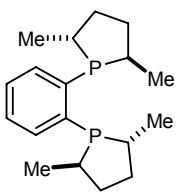

$(R, R)-$ Me-DuPhos (L3)

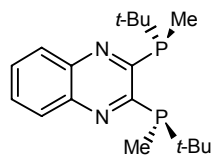
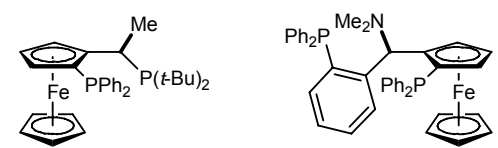

$(R, R)-$ Quinox-P* $($ L4)

Josiphos SL-J002-1 (L5)

Taniaphos SL-T001-1 (L6)

$\begin{array}{ccccc}\text { entry } & \text { bisphosphine } & \mathbf{2 a : 3 ^ { b }} & \mathrm{dr}^{b} & \text { ee (\%) } \\ 1 & \text { L1 } & 11: 1 & 1: 1 & 43,50 \\ 2 & \text { L2 } & 13: 1 & 1: 1 & 67,67 \\ 3 & \text { L3 } & 24: 1 & 1: 1 & 27,17 \\ 4 & \text { L4 } & 17: 1 & 1: 1 & -60,-92 \\ 5 & \text { L5 } & 12: 1 & 1: 1 & 92,93 \\ 6 & \text { L6 } & 7: 1 & 5: 1 & 93,60\end{array}$

${ }^{a}$ Reactions were conducted using $0.10 \mathrm{mmol}$ of 1a. ${ }^{b}$ Determined by ${ }^{1} \mathrm{H}$ NMR analysis of the unpurified reaction mixtures. ${ }^{c}$ Determined by chiral HPLC analysis.

those containing azines such as pyridines (products $\mathbf{2 c}$ and $\mathbf{2 k}$ ), isoquinoline (products 2d-2g), two different isomeric dimethoxypyrimidines (products $\mathbf{2} \mathbf{h}$ and $\mathbf{2} \mathbf{i}$ ), and quinoxaline (product 2l). A vinylthiazole also smoothly underwent the reaction (product $\mathbf{2 j}$ ). With acyclic ketones, the diastereoselectivity of the reaction appears to be dependent on the steric properties of the azaarene, with diastereoselectivity increasing from pyridine to quinoline to isoquinoline (compare diastereomeric ratios for products $\mathbf{2 c}, \mathbf{2 a}$, and $\mathbf{2 d}$ ). In the coupling of 2vinylpyridine with acetophenone, the two diastereomeric products $\mathbf{2 c a}$ and $\mathbf{2 c b}$ were isolated with high enantioselectivities ( $>99 \%$ and $92 \%$ ee, respectively). Regarding the electrophile, the process is tolerant of acyclic ketones containing various alkyl, aryl, or heteroaryl substituents (products 2a2g). In addition, cyclic ketones are viable substrates, as exemplified by the successful use of two indanones (products $\mathbf{2 h}$ and $2 \mathbf{i}$ ), 4-chromanone (product $2 \mathbf{j}$ ), 4-thiochromanone (product 2k), and tetralone (product 2l).

Interestingly, the absolute stereochemistries of isoquinolinecontaining products $\mathbf{2 d}-\mathbf{2} \mathbf{g}$ are opposite to those of quinolinecontaining products $\mathbf{2 a}$ and $\mathbf{2} \mathbf{b}$, even though the same enantiomer of ligand $\mathbf{L 6}$ was employed throughout. ${ }^{11}$ In addition, the diastereochemical outcomes of the reactions producing $\mathbf{2 h}-\mathbf{2 l}$ are different from those resulting in $\mathbf{2 a}, \mathbf{2} \mathbf{b}$, and $\mathbf{2 d - 2 \mathbf { g }}{ }^{11}$ Assuming that the reactions proceed via Zimmerman-Traxlertype transition states where the larger aryl group of the ketone occupies a pseudoequatorial position, ${ }^{13}$ Figure 2 depicts conformations that are consistent with these observations. The stereochemical outcomes of the reactions producing $\mathbf{2 a}, \mathbf{2} \mathbf{b}$,
Chart 1. Reaction Scope with Vinylazaarenes ${ }^{a}$

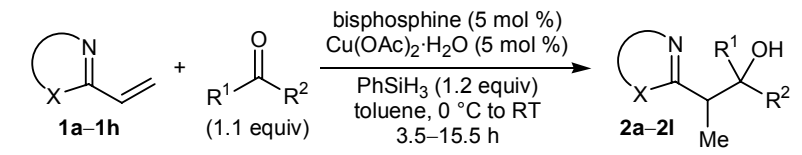

Using SL-T001-1 (L6)<smiles>C[C@H](c1ccc2ccccc2n1)C(C)(O)c1ccccc1</smiles>

2a $60 \%$ $4: 1 \mathrm{dr}, 93 \%$ ee

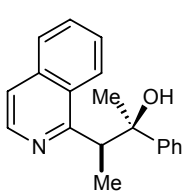

2d $76 \%$ $12: 1 \mathrm{dr}, 90 \%$ ee 2b $60 \%$ $8: 1 \mathrm{dr}, 96 \%$ ee<smiles>CC(c1ccccn1)C(C)(O)c1ccccc1</smiles>

2ca (2cb) $65 \%(31 \%)$ $2: 1 \mathrm{dr},>99 \%$ ee $(92 \%$ ee $)$

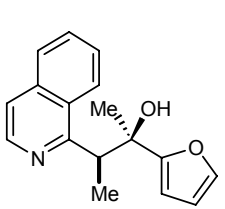

2g $76 \%$ $12: 1 \mathrm{dr}, 89 \%$ ee

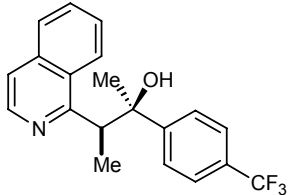

2e $82 \%$ $9: 1 \mathrm{dr},>99 \%$ ee

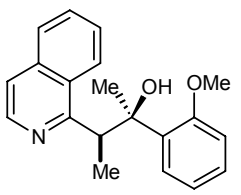

2f $78 \%$

$>19: 1 \mathrm{dr}, 97 \%$ ee
Using $(R, R)$-Quinox-P* (L4):<smiles></smiles>

2j $68 \%$ $10: 1 \mathrm{dr}, 93 \%$ ee<smiles>[Y4]C(c1ccc(C(=O)OCC)cn1)C1(O)CCSc2ccccc21</smiles>

2k $66 \%$

$4: 1 \mathrm{dr}, 91 \%$ ee<smiles>COc1cc([C@@H](C)[C@]2(O)CCc3cc(F)ccc32)nc(OC)n1</smiles>

2i $63 \%$<smiles>C[C@H](c1ccc2ccccc2n1)[C@@](O)(Cc1ccccc1)c1ccccc1</smiles>

${ }^{a}$ Reactions were conducted using $0.30-0.40 \mathrm{mmol}$ of $\mathbf{1 a}-\mathbf{1 h}$. Cited yields are of pure isolated major diastereomers. Diastereomeric ratios were determined by ${ }^{1} \mathrm{H}$ NMR analysis of the unpurified reaction mixtures. Enantiomeric excesses were determined by chiral HPLC analysis.
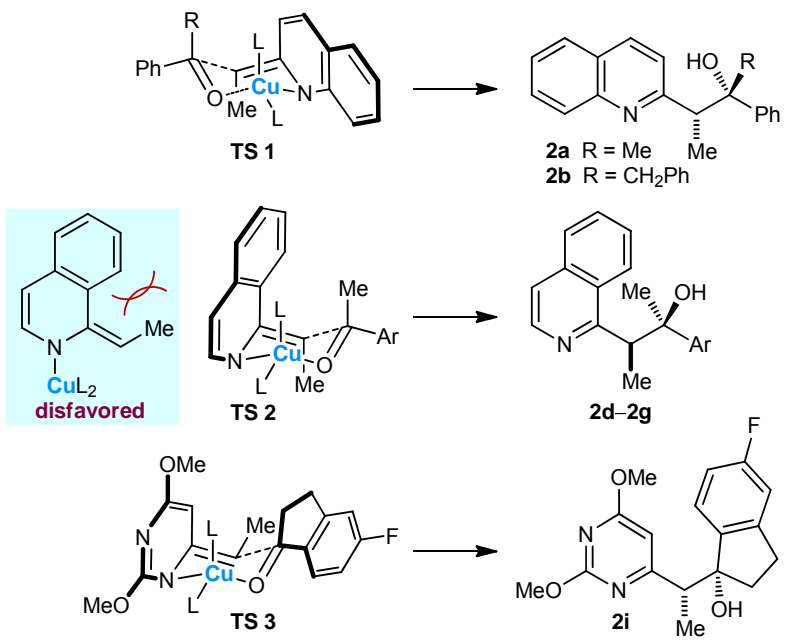

Figure 2. Rationalization of stereochemical outcomes. 
Chart 2. Reductive Coupling of $\beta$-Substituted Alkenylazaarenes with Ketones ${ }^{a}$

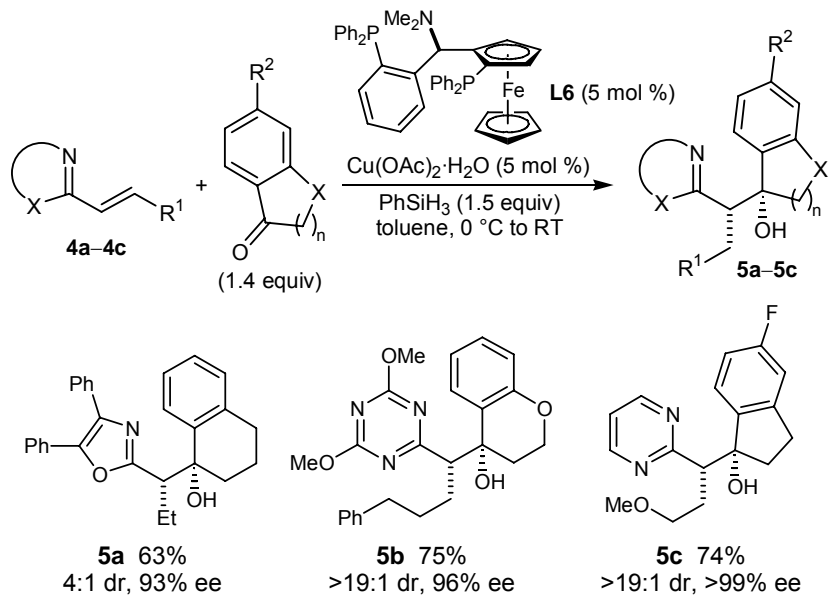

${ }^{a}$ Reactions were conducted using $0.30 \mathrm{mmol}$ of $\mathbf{4 a}-\mathbf{4 c}$. Cited yields are of pure isolated major diastereomers. Diastereomeric ratios were determined by ${ }^{1} \mathrm{H}$ NMR analysis of the unpurified reaction mixtures. Enantiomeric excesses were determined by chiral HPLC analysis.

and $2 \mathbf{d}-\mathbf{2 g}$ are consistent with the participation of $Z$ azaallylcopper species ${ }^{14}$ (TS 1 and TS 2), though the reasons for the opposite sense of enantioinduction in TS 2 compared with TS 1 are not clear at this time. Furthermore, while the preference for the $Z$-azaallylcopper species in TS $\mathbf{2}$ is readily explained by the severe $A_{1,3}$-strain ${ }^{15}$ that would disfavor the corresponding $E$-azaallylcopper species, a similar argument cannot be used to explain the same preference in TS 1. For reactions producing $\mathbf{2 h}-\mathbf{2 l}$, reaction through the $E$ azaallylcopper species (or $Z$-azaallylcopper species in the case of $\mathbf{2 j}$ ) appears to be favored, as in TS $\mathbf{3}$ for the formation of $\mathbf{2 i}$. The interplay between the steric and/or electronic properties of the alkenylazaarene and ligand, and the resulting effect on the stereochemical outcome, are clearly complex. In addition, while the preceding discussion has been based upon the assumption that chair-like transition states are operative, reaction through boat-like structures cannot be excluded.

Notably, the process is not limited to vinylazaarenes; $\beta$ substituted alkenylazaarenes are also effective coupling partners (Chart 2). For example, alkenylazaarenes $\mathbf{4 a}-\mathbf{4} \mathbf{c}^{12}$ containing methyl, phenethyl, or allylic ether groups smoothly undergo reductive coupling to deliver products $\mathbf{5 a}-\mathbf{5 c}$, respectively, in high enantioselectivities. ${ }^{11}$ Furthermore, these products contain additional examples of azaarenes not utilized in Chart 1, such as diphenyloxazole (product 5a), a dimethoxytriazine (product 5b), and 1,3-pyrimidine (product 5c).

In summary, we have described the first examples of catalytic enantioselective reductive couplings of alkenylazaarenes. The scope of this process is broad, with eleven different types of azaarenes and a range of acyclic and cyclic ketones having been shown to be effective coupling partners. $\beta$-Substitution on the alkene is tolerated, and the reactions proceed under mild conditions to deliver products in good to high levels of diastereo- and enantioselection. These features should be advantageous for application of this process in the preparation of novel enantioenriched chiral azaarene-containing building blocks.
Supporting Information. Experimental procedures, full spectroscopic data for all new compounds, and crystallographic data in cif format. This material is available free of charge via the Internet at http://pubs.acs.org.

\section{AUTHOR INFORMATION}

\section{Corresponding Author}

h.lam@ed.ac.uk

\section{ACKNOWLEDGMENT}

This work was supported by the University of Edinburgh, the EPSRC, and the ERC (Starting Grant No. 258580). We thank Matthias Lotz (Solvias AG) for kind donations of $\mathbf{L 5}$ and $\mathbf{L 6}$. The EPSRC is gratefully acknowledged for the award of a Leadership Fellowship to H. W. L. We thank Iain D. Roy and Boris Michel (University of Edinburgh) for assistance in the preparation of substrates, and Dr. Gary S. Nichol and Professor Simon Parsons (University of Edinburgh) for assistance with X-ray crystallography. We are grateful to the EPSRC National Mass Spectrometry Service Centre at the University of Wales, Swansea, for providing high resolution mass spectra.

\section{REFERENCES}

(1) Rupnicki, L.; Saxena, A.; Lam, H. W. J. Am. Chem. Soc. 2009, 131, 10386-10387.

(2) Pattison, G.; Piraux, G.; Lam, H. W. J. Am. Chem. Soc. 2010, $132,14373-14375$.

(3) For related contributions from elsewhere, see: (a) Houpis, I. N.; Lee, J.; Dorziotis, I.; Molina, A.; Reamer, B.; Volante, R. P.; Reider, P. J. Tetrahedron 1998, 54, 1185-1195. (b) Baschieri, A.; Bernardi, L.; Ricci, A.; Suresh, S.; Adamo, M. F. A. Angew. Chem., Int. Ed. 2009, 48, 9342-9345. (c) Sun, H.-W.; Liao, Y.-H.; Wu, Z.-J.; Wang, H.-Y.; Zhang, X.-M.; Yuan, W.-C. Tetrahedron 2011, 67, 3991-3996.

(4) For reviews of copper hydride chemistry, see: (a) Lipshutz, B. H. Synlett 2009, 509-524. (b) Deutsch, C.; Krause, N.; Lipshutz, B. H. Chem. Rev. 2008, 108, 2916-2927. (c) Rendler, S.; Oestreich, M. Angew. Chem., Int. Ed. 2007, 46, 498-504. (d) Lipshutz, B. H. In Modern Organocopper Chemistry; Wiley-VCH Verlag GmbH: 2002, p 167-187.

(5) For intermolecular copper-catalyzed reductive aldol reactions, see: (a) Zhao, D.; Oisaki, K.; Kanai, M.; Shibasaki, M. Tetrahedron Lett. 2006, 47, 1403-1407. (b) Welle, A.; Diez-Gonzalez, S.; Tinant, B.; Nolan, S. P.; Riant, O. Org. Lett. 2006, 8, 6059-6062. (c) Chuzel, O.; Deschamp, J.; Chausteur, C.; Riant, O. Org. Lett. 2006, 8, 59435946. (d) Deschamp, J.; Chuzel, O.; Hannedouche, J.; Riant, O. Angew. Chem., Int. Ed. 2006, 45, 1292-1297. (e) Zhao, D.; Oisaki, K.; Kanai, M.; Shibasaki, M. J. Am. Chem. Soc. 2006, 128, 14440-14441.

(6) For intramolecular copper-catalyzed or -mediated reductive aldol reactions, see: (a) Chiu, P.; Szeto, C.-P.; Geng, Z.; Cheng, K.-F. Org. Lett. 2001, 3, 1901-1903. (b) Chiu, P.; Leung, S. K. Chem. Commun. 2004, 2308-2309. (c) Lam, H. W.; Joensuu, P. M. Org. Lett. 2005, 7, 4225-4228. (d) Lam, H. W.; Murray, G. J.; Firth, J. D. Org. Lett. 2005, 7, 5743-5746. (e) Lipshutz, B. H.; Amorelli, B.; Unger, J. B. J. Am. Chem. Soc. 2008, 130, 14378-14379. (f) Deschamp, J.; Riant, O. Org. Lett. 2009, 11, 1217-1220. (g) Li, N.; Ou, J.; Miesch, M.; Chiu, P. Org. Biomol. Chem. 2011, 9, 6143-6147. (h) Ou, J.; Wong, W.-T.; Chiu, P. Tetrahedron 2012, 68, 3450-3456. (i) Deschamp, J.; Hermant, T.; Riant, O. Tetrahedron 2012, 68, 34573467.

(7) Relevant reviews on the reductive aldol reaction: (a) Nishiyama, H.; Ito, J.-i. Chem. Commun. 2010, 203-212. (b) Han, S B.; Hassan, A.; Krische, M. J. Synthesis 2008, 2669-2679. (c) Garner, S. A.; Han, S. B.; Krische, M. J. In Modern Reduction Methods Wiley-VCH Verlag GmbH \& Co. KGaA: 2008, p 387-417. (d) Nishiyama, H.; Shiomi, T. Top. Curr. Chem. 2007, 279, 105-137. (e) Ngai, M.-Y.; Kong, J.-R.; Krische, M. J. J. Org. Chem. 2007, 72, 
1063-1072. (f) Jang, H.-Y.; Krische, Michael J. Eur. J. Org. Chem. 2004, 3953-3958. (g) Jang, H.-Y.; Krische, Michael J. Eur. J. Org. Chem. 2004, 3953-3958. (h) Jang, H.-Y.; Krische, M. J. Acc. Chem. Res. 2004, 37, 653-661. (i) Chiu, P. Synthesis 2004, 2210-2215. (j) Huddleston, R. R.; Krische, M. J. Synlett 2003, 12-21. (k) Motherwell, W. B. Pure Appl. Chem. 2002, 74, 135-142.

(8) For enantioselective copper-catalyzed reductive Michael reactions, see: Oswald, C. L.; Peterson, J. A.; Lam, H. W. Org. Lett. 2009, 11, 4504-4507.

(9) For enantioselective copper-catalyzed reductive Mannich reactions, see: Du, Y.; Xu, L.-W.; Shimizu, Y.; Oisaki, K.; Kanai, M.; Shibasaki, M. J. Am. Chem. Soc. 2008, 130, 16146-16147.

(10) Komanduri, V.; Grant, C. D.; Krische, M. J. J. Am. Chem. Soc. 2008, 130, 12592-12593.

(11) Where indicated, the relative and absolute stereochemistries of the products obtained herein were assigned by analogy with those of products $\mathbf{2 a}, \mathbf{2 b}, \mathbf{2 d}, \mathbf{2 e}, \mathbf{2 j}$, and $\mathbf{5 c}$, which were determined by X-ray crystallography using a copper radiation source (see Supporting Information for details). The stereochemistry of 2l (obtained using ligand L5) was assigned by analogy with the product obtained using ligand L6, which was the same major enantiomer of $2 \mathbf{l}$ but in $2: 1 \mathrm{dr}$ and $73 \%$ ee.

(12) See Supporting Information for the structures of $\mathbf{1 b}-\mathbf{1 h}$ and 4a-4c.

(13) Zimmerman, H. E.; Traxler, M. D. J. Am. Chem. Soc. 1957, 79, 1920-1923.

(14) For a review of 1-azaallylic anions in heterocyclic chemistry, see: Mangelinckx, S.; Giubellina, N.; De Kimpe, N. Chem. Rev. 2004, 104, 2353-2400.

(15) For a review of allylic 1,3-strain as a stereocontrolling element in reactions, see: Hoffmann, R. W. Chem. Rev. 1989, 89, 1841-1860. 

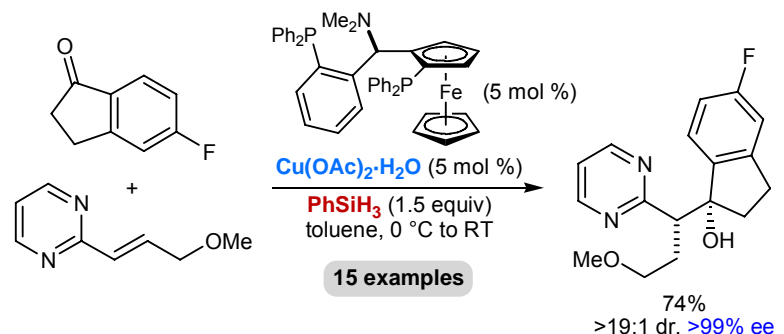